\title{
Implementasi Multimedia Development Life Cycle Pada Aplikasi Pembelajaran Multimedia Interaktif Algoritma dan Pemrograman Dasar Untuk Mahasiswa Berkebutuhan Khusus Berbasis Android
}

\author{
Shidqie Alisyafiq ${ }^{1^{*}}$, Bella Hardiyana ${ }^{2}$, Rani Puspita Dhaniawaty ${ }^{3}$ \\ ${ }^{123}$ Universitas Komputer Indonesia, Indonesia \\ Email: (alisyafiq@mahasiswa.unikom.ac.id)
}

\section{INFORMASI ARTIKEL}

Terkirim 06-Agustus-2021

Revisi 24-Agustus-2021

Diterima 06-Sept-2021

\section{Kata kunci:}

Multimedia, Algoritma,

Media Pembelajaran

\begin{abstract}
ABSTRAK
Tujuan membangun Aplikasi Multimedia Pembelajaran Interkatif Algoritma dan Pemrograman Dasar diharapkan bisa menciptakan suasana baru agar proses belajar lebih efektif dan dosen tidak mempunyai hambatan dalam memvisualisasikan materi sehingga mahasiswa berkebutuhan khusus lebih mudah menyerap materi yang diajarkan oleh dosen. Pemilihan multimedia interaktif sebagai media pembelajaran adalah untuk sebisa mungkin melengkapi serta mendukung unsurunsur seperti tujuan materi, metode, dan alat penilaian yang ada dalam proses belajar mengajar konvensional. Dalam melakukan penelitian ini peneliti menggunakan metode pendekatan Multimedia Development Life Cycle (MDLC) yang terdiri dari enam tahap yaitu pengonsepan, perancangan, pengumpulan materi, pembuatan, pengujian, dan pendistribusian. Subjek dari penelitian ini adalah mahasiswa berkebutuhan khusus yang ada di lingkungan Prodi Sistem Informasi Universitas Komputer Indonesia (Unikom). Hasil dari penelitian ini berupa aplikasi pembelajaran sebagai alat bantu bagi dosen dalam menyampaikan materi Algoritma dan Pemrograman Dasar sehingga menciptakan suasana baru di kelas dan diharapkan perkuliahan menjadi lebih efektif bagi mahasiswa berkebutuhan khusus.
\end{abstract}

(7) (2) This is an open access article distributed under the Creative Commons 4.0 Attribution License, This license lets others remix, tweak, and build upon your work even for commercial purposes, as long as they credit you and license their new creations under the identical terms $@ 2018$ by author and Universitas Negeri Padang.

\section{Pendahuluan}

Pendidikan bagi mahasiswa berkebutuhan khusus pada jenjang perguruan tinggi diperlukan penyesuaian dibeberapa bagian, seperti materi pembelajaran, media yang digunakan, proses pembelajaran yang diberikan dan proses penilaian (Rohman, 2019). Maka dari itu, beberapa bagian tersebut menjadi acuan untuk perguruan tinggi terutama Prodi Sistem Informasi UNIKOM, baik dalam kegiatan akademik maupun non-akademik, untuk dapat memenuhi kebutuhan mahasiswa berkebutuhan khusus selama melakukan pembelajaran dilingkungan kampus. Mahasiswa berkebutuhan khusus ini masuk ke klasifikasi mahasiswa autis. Salah satu bentuk tanggung jawab kampus dalam memberikan pelayanan yang layak bagi mereka adalah dengan menyediakan pembelajaran yang sesuai dengan kebutuhan dan keunikan mereka.

Pembelajaran yang dimaksud adalah media pembelajaran menggunakan multimedia interaktif. Multimedia interaktif merupakan suatu media komprehensif dengan alat pengontrol dimana pengguna dapat memilih apa yang dikehendaki untuk proses selanjutnya (Jauhari, 2009). Tujuannya agar proses belajar mengajar konvensional terlengkapi dan terdukung dari segi tujuan materi, metode dan alat penilaiannya (Ambarwati \& Darmawel, 2020). 
Adapun penelitian serupa dengan penelitian ini dilakukan oleh Mukhammad Luqman Hakim yang berjudul "Multimedia Interaktif Bagi Siswa Berkebutuhan Khusus". Penelitian tersebut menggunakan metode pendekatan deskriptif kualitatif. Pendekatan ini mencatat pemanfaatan media dalam pembelajaran Pendidikan Agama Islam di SLB Nurul Ikhsan Ngadiluwih yang dilakukan kepada 10 siswa, guru mata pelajaran Pendidikan Agama Islam dan Kepala Sekolah. Dari pembuatan media pembelajaran tersebut dapat disimpulkan bahwa dengan tampilan media yang menarik, siswa menjadi lebih termotivasi dalam belajar (Hakim, 2020).

Seiring berkembangnya informasi teknologi saat ini, kita dapat memanfaatkan media seperti ponsel pintar Android. Ponsel pintar dapat dikategorikan sebagai mini-komputer yang memiliki banyak fungsi dan dapat digunakan kapanpun dan dimanapun (Barakati, 2013). Android banyak digunakan khalayak masyarakat karena memang harganya yang relatif lebih murah. Inilah yang menjadi alasan penulis dalam memilih sistem operasi Android sebagai teknologi dari multimedia pembelajaran interaktif yang dikembangkan. Adapun alasan pemilihan mata kuliah Algoritma dan Pemrograman Dasar adalah karena Algoritma dan Pemrograman Dasar merupakan fondasi dari ilmu komputer yang mempelajari tentang bagaimana memecahkan suatu masalah dengan menggunakan bahasa pemrograman (Isroqmi, 2017). Jadi sangatlah penting untuk mahasiswa belajar tentang Algoritma dan Pemrograman Dasar sebelum melanjutkan ke mata kuliah lain yang ada di Prodi Sistem Informasi.

\section{Metode}

Metode pendekatan sistem yang digunakan pada penelitian ini adalah metode Multimedia Development Life Cycle. Pada metode ini terdapat enam tahapan yaitu pengonsepan (concept), perancangan (design), pengumpulan materi (material collecting), pembuatan (assembly), pengujian (testing) dan pendistribusian (distribution).

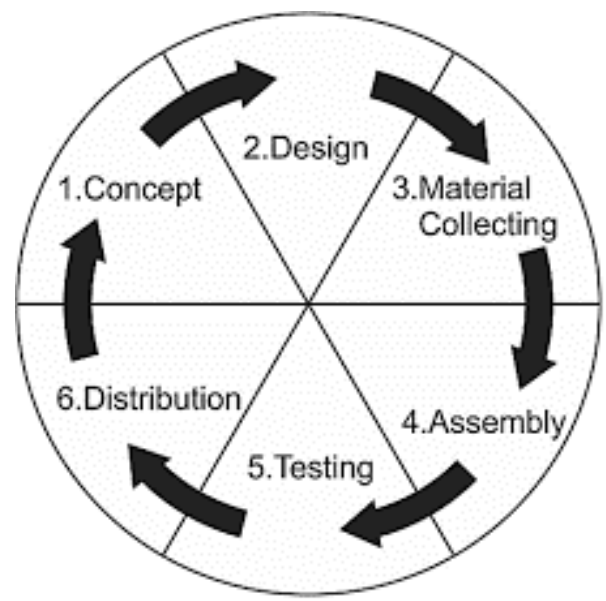

Gambar 1. Tahapan Metode MDLC (Mustika, Sugara, \& Pratiwi, 2018)

Berikut merupakan 6 (enam) tahapan kegiatan Multimedia Development Life Cycle (MDLC) yang dilakukan, yaitu : 
1. Konsep (Concept) : Tahapan ini mendeskripsikan tujuan dan konsep aplikasi serta mengidentifikasi pengguna program.

2. Perancangan (Design) : Tahapan ini merupakan pembuatan rancangan mengenai struktur program, gaya atau tema, tampilan, serta kebutuhan dalam pembuatan aplikasi.

3. Pengumpulan Bahan (Material Collecting) : Tahapan ini merupakan pengumpulan bahan yang sesuai dengan kebutuhan aplikasi yang dikerjakan. Bahan tersebut dapat berupa gambar, video, audio, animasi dan lain-lain.

4. Pembuatan (Assembly) : Tahapan ini merupakan tahap penyusunan semua bahan yang telah dikumpulkan. Pembuatan aplikasi dibuat berdasarkan pada tahap desain.

5. Pengujian (Testing) : Tahap pengujian merupakan tahap menjalankan aplikasi dan memeriksa apakah terdapat error atau tidak.

6. Pendistribusian (Distribution) : Tahapan ini merupakan tahap analisis untuk pengembangan aplikasi yang sudah jadi agar menjadi lebih baik.

Dalam praktiknya, keenam tahapan tersebut tidak harus berurutan, tahapan-tahapan tadi dapat saling bertukar posisi. Namun, tahapan konsep tetap menjadi tahapan pertama yang harus dikerjakan (Mustika et al., 2018).

\section{Hasil Penelitian dan Pembahasan}

Kurang optimalnya penggunaan media pembelajaran yang sesuai dengan kebutuhan mahasiswa berkebutuhan khusus merupakan masalah inti yang dihadapi oleh Prodi Sistem Informasi UNIKOM. Penelitian menggunakan multimedia interaktif sudah banyak digunakan para peneliti untuk membantu keberlangsungan pembelajaran bagi anak berkebutuhan khusus. Desain yang menarik dan penggunaan multimedia interaktif merupakan faktor keberhasilan yang dapat meningkatkan keaktifan pemahaman siswa yang menderita tuna grahita ringan (Maulidiyah, 2020).

Penelitian yang serupa dilakukan oleh Farah Nayla Maulidiyah dengan judul "Media Pembelajaran Multimedia Interaktif untuk Anak Tunagrahita Ringan". Metode pendekatan yang digunakan pada penelitian tersebut adalah metode Single Subject Research (SSR), metode ini melakukan sebuah eksperimen dengan menggunakan subjek tunggal untuk mengetahui umpan balik dari suatu perlakuan yang sudah diberikan. Subjek dari penelitian ini adalah anak tunagrahita ringan yang mempunyai tingkat intelektual di bawah rata rata yaitu IQ 50 - 70. Menurut penelitian tersebut, disimpulkan bahwa antusias anak dalam belajar meningkat karena multimedia interaktif yang meliputi audio dan visual membantu keberhasilan penyampaian materi (Maulidiyah, 2020).

Kemudian terdapat penelitian serupa yang lain yang dilakukan oleh Bella Hardiyana yang berjudul "Application of IPS Learning about Humans and Geographical Environment Based on Multimedia“. Metode yang digunakan yaitu metode deskriptif dan menggunakan metode prototype dalam metode pengembangan sistemnya. Penelitian ini menyimpulkan bahwa aplikasi tersebut mempermudah guru dalam menjelaskan dan mengilustrasikan materi tanpa harus menggambar atau menulis (Hardiyana \& Yudistira, 2018).

Kedua penelitian tersebut menjadi alasan penulis memilih multimedia interaktif sebagai media pembelajaran yang dirancang dan dikembangkan. Berikut rincian tahapan yang digunakan penulis 
dalam merancang dan mengembangkan aplikasi multimedia pembelajaran ini berdasarkan metode penelitian yang digunakan.

1. Konsep (Concept)

Aplikasi ini menggunakan multimedia interaktif sebagai media pembelajaran pada mata kuliah Algoritma dan Pemrograman Dasar untuk mahasiswa berkebutuhan khusus yang ada di Program Studi Sistem Informasi UNIKOM. Prosedur dalam proses pembelajaran tidak terlalu banyak berubah hanya media pembelajaran dibuat lebih interaktif dan menarik yang diharapkan dapat membuat mahasiswa berkebutuhan khusus lebih mudah memahami mata kuliah Algoritma dan Pemrograman Dasar.

2. Perancangan (Design)

Tahapan perancangan ini menghasilkan rancangan penelitian menggunakan struktur navigasi dan storyboard sebagai gambaran aplikasi yang akan diimplementasikan nantinya . Desain yang dibuat tentunya penulis buat semenarik mungkin agar mahasiswa berkebutuhan khusus tertarik untuk menggunakan media pembelajaran multimedia interaktif ini. Untuk perancangan storyboard dan flowchart dapat dilihat pada gambar berikut :

a. Struktur Navigasi

Berikut merupakan struktur navigasi dari Aplikasi Multimedia Pembelajaran Interaktif Algoritma dan Pemrograman Dasar:

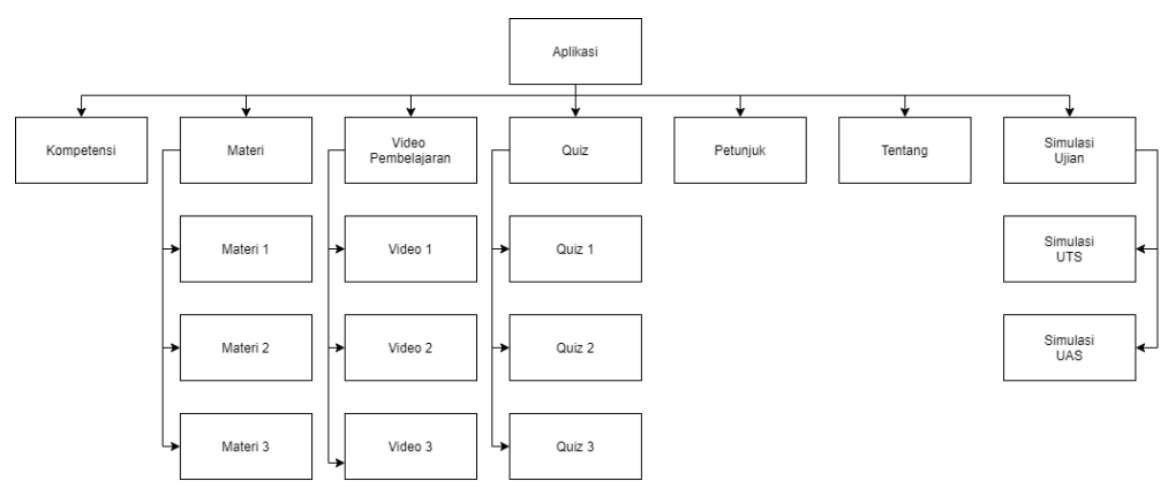

Gambar 2. Perancangan awal Struktur Navigasi

\section{b. Storyboard}

Perancangan storyboard pada halaman utama dan beberapa menu yang terdapat pada Aplikasi AMPI Algoritma. Berikut merupakan desain tampilan storyboard pada AMPI Algoritma. 

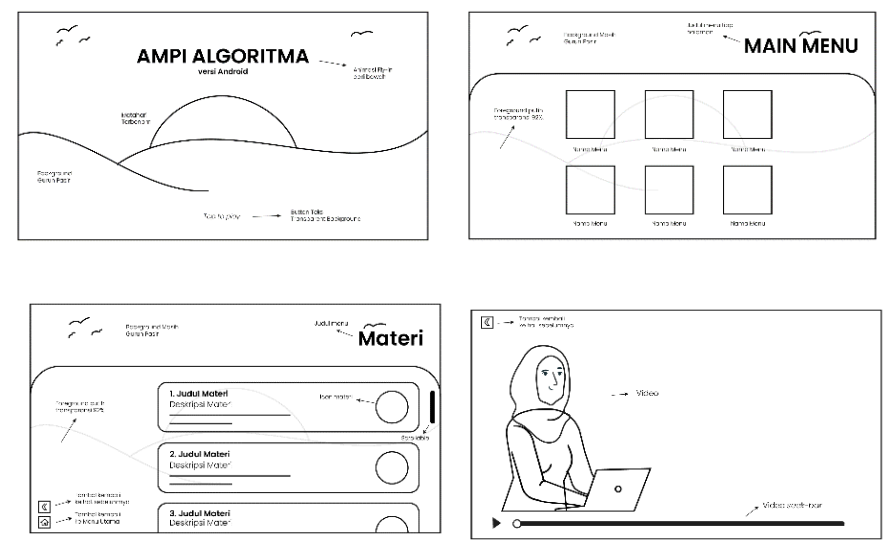

Gambar 3. Perancangan Storyboard

\section{Pengumpulan Bahan (Material Collecting)}

Pada tahapan ini dilakukan pengumpulan bahan yang berhubungan dengan materi pembelajaran. Materi pembelajaran didapatkan dari tim dosen Prodi Sistem Informasi UNIKOM, sedangkan bahan-bahan terkait dengan pembuatan aplikasi seperti ilustrasi gambar didapatkan dari internet dengan memastikan bahwa ilustrasi tersebut bebas dari hak cipta. Kemudian, ilustrasi gambar yang telah dikumpulkan akan dimodifikasi dengan menggunakan Adobe Photoshop 2020, Adobe Illustrator 2020, Adobe After Effect 2020 dan VideoScribe yang kemudian diubah menjadi ilustrasi atau animasi baru.

4. Pembuatan (Assembly)

Tahap assembly atau pembuatan merupakan tahap pembuatan keseluruhan bahan multimedia atau hasil penerapan dari proses perancangan yang sudah dilakukan sebelumnya (Nurajizah, 2016). Adapun perangkat lunak yang digunakan untuk membuat aplikasi multimedia pembelajaran interaktif ini adalah Articulate Storyline 3. Menu utama pada aplikasi ini dibagi menjadi tujuh menu yaitu, kompetensi, materi, video pembelajaran, quiz, petunjuk, tentang dan simulasi ujian. Tiap halaman menu dibuat semenarik dan seinteraktif mungkin agar para mahasiswa berkebutuhan khusus dapat lebih mudah menyerap materi yang diajarkan.

\section{a. Halaman Intro/Opening}

Saat pengguna masuk aplikasi, aplikasi akan menampilkan tampilan intro/opening berupa animasi pendek yang kemudian akan menghimbau pengguna untuk menekan tombol 'Tap to Play' untuk memainkan aplikasi.


Gambar 4. Halaman Pembuka dan Animasi Opening 
b. Halaman Menu Utama

Menu utama yang terdiri dari menu kompetensi, materi, video pembelajaran, quiz, simulasi ujian, petunjuk dan tentang.

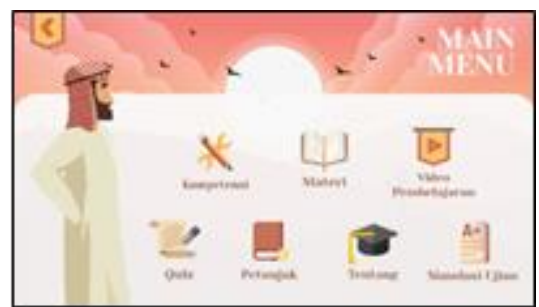

Gambar 5. Halaman Menu Utama

c. Halaman Materi

Tampilan menu Materi dibagi menjadi 7 materi pokok. Materi 1 sampai dengan 4 yaitu materi yang diberikan sebelum UTS dan materi 5 sampai dengan 7 yaitu materi yang diberikan setelah UTS. Masing-masing materi disajikan dengan cara yang menarik dan interaktif contohnya seperti menggunakan fitur drag \& drop.
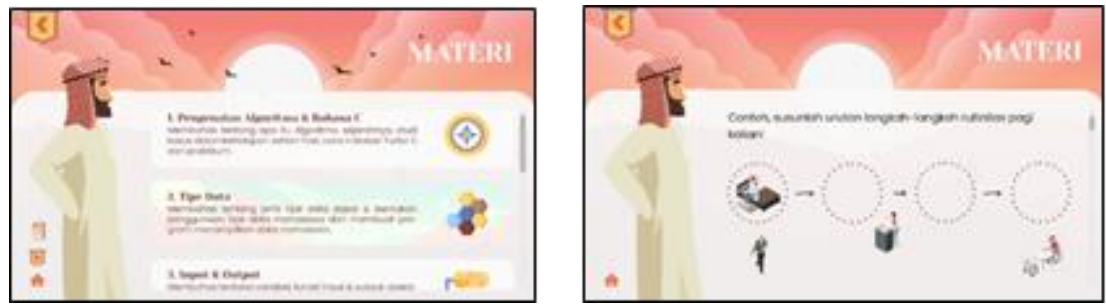

Gambar 6. Fitur Drag \& Drop pada Materi Algoritma

d. Halaman Video Pembelajaran

Menu Video Pembelajaran berisi mengenai video-video materi teoritis yang dibuat oleh tim dosen dan mahasiswa Prodi Sistem Informasi Unikom.
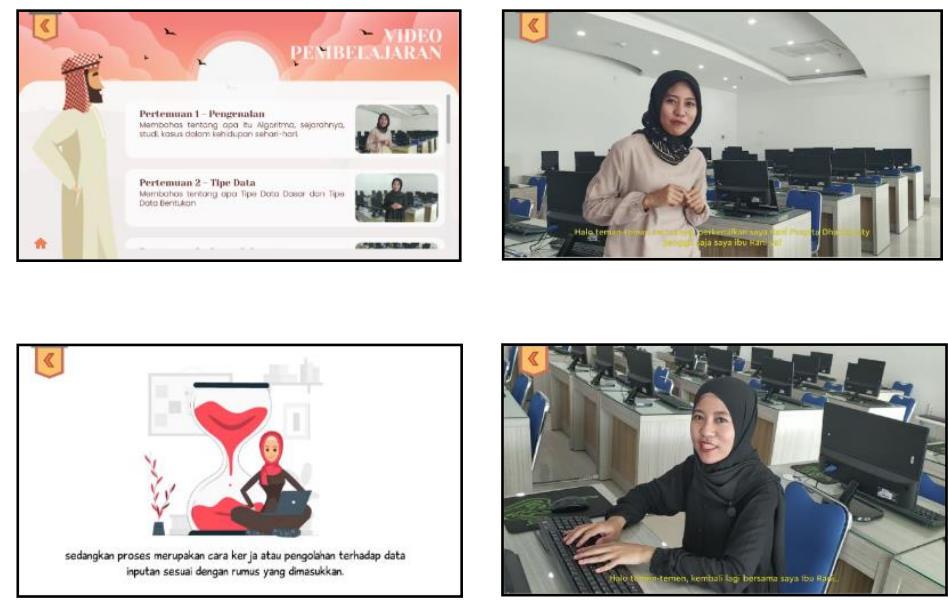

Gambar 7. Halaman Video Pembelajaran dan Video Materi 
e. Halaman Quiz

Dalam menu Quiz berisi mengenai latihan soal dari materi dan video penjelasan yang telah dibahas sebelumnya. Jika pengguna menjawab benar pada soal maka akan muncul tampilan "Betul Sekali" dan klik continue untuk melanjutkan ke soal berikutnya. Tetapi jika pengguna menjawab salah pada soal maka akan muncul tampilan "Kurang Tepat". Soal-soal kuis disajikan dalam beberapa tipe soal, seperti pilihan ganda, multiple response, true or false, fill in the blank, drag and drop dan sequence.
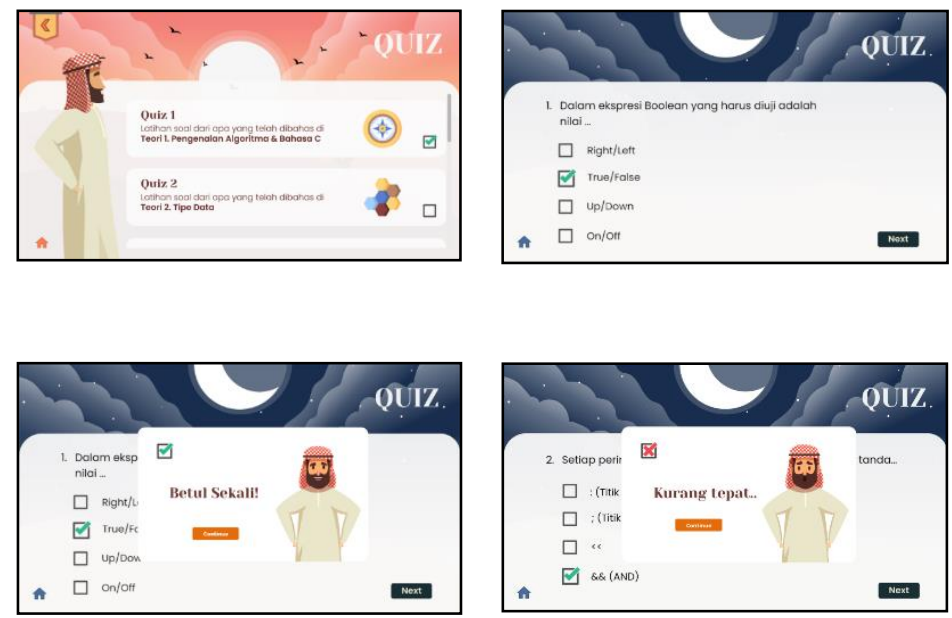

Gambar 8. Halaman Menu Quiz

\section{f. Halaman Simulasi Ujian}

Tampilan Menu Simulasi Ujian, terdapat dua bagian yaitu Simulasi UTS dan Simulasi UAS. Kedua Simulasi tersebut terdapat 25 soal dalam bentuk pilihan ganda yang perlu dikerjakan oleh pengguna, sehingga pengguna dapat mengetahui hasil evaluasi dari pembelajaran yang sudah diterima. Jika nilai lebih dari sama dengan nilai KKM 80\% (200 point), maka akan menampilkan "kamu lulus". Tetapi jika nilai yang didapatkan dibawah KKM 80\% (200 poin), maka akan menampilkan "kamu belum lulus".


Gambar 9. Halaman Simulasi Ujian

\section{Pengujian (Testing)}

Tahap pengujian perlu dilakukan untuk memastikan apakah aplikasi telah sesuai dan berfungsi dengan benar. Metode pengujian yang dilakukan dalam menguji aplikasi ini adalah pengujian black box. Berikut ini adalah hasil dari pengujian aplikasi: 
Tabel 1. Hasil Pengujian Black Box

\begin{tabular}{|c|c|c|c|c|}
\hline No. & $\begin{array}{c}\text { Komponen yang } \\
\text { Diuji }\end{array}$ & Skenario pengujian & Pengujian & Keterangan \\
\hline 1 & Halaman Awal & Memilih Tombol "Tap to Play" & Blackbox & $(\sqrt{ })$ Berhasil \\
\hline \multirow{9}{*}{2} & \multirow{9}{*}{ Halaman Utama } & Memilih Tombol "Navigasi" & Blackbox & $(\sqrt{ })$ Berhasil \\
\hline & & Memilih Tombol "Materi" & Blackbox & $(\sqrt{ })$ Berhasil \\
\hline & & Memilih Tombol "Kompetensi" & Blackbox & $(\sqrt{ })$ Berhasil \\
\hline & & Memilih Tombol "Video & Blackbox & $(\sqrt{ })$ Berhasil \\
\hline & & Pembelajaran" & & \\
\hline & & Memilih Tombol "Quiz" & Blackbox & $(\sqrt{ })$ Berhasil \\
\hline & & Memilih Tombol "Petunjuk" & Blackbox & $(\sqrt{)}$ Berhasil \\
\hline & & Memilih Tombol "Tentang" & Blackbox & $(\sqrt{)}$ Berhasil \\
\hline & & Memilih Tombol "Simulasi Ujian" & Blackbox & $(\sqrt{ })$ Berhasil \\
\hline \multirow{7}{*}{3} & \multirow{7}{*}{ Halaman Materi } & Memilih Tombol "Home" & Blackbox & $(\sqrt{ })$ Berhasil \\
\hline & & Memilih Tombol "Video & Blackbox & $(\sqrt{ })$ Berhasil \\
\hline & & Pembelajaran" & & \\
\hline & & Memilih Tombol "Simulasi Ujian" & Blackbox & $(\sqrt{ })$ Berhasil \\
\hline & & Memilih Tombol "Kembali" & Blackbox & $(\sqrt{ })$ Berhasil \\
\hline & & Memilih Tombol "Materi 1" & Blackbox & $(\sqrt{ })$ Berhasil \\
\hline & & Mendrag Bagian Puzzle & Blackbox & $(\sqrt{ })$ Berhasil \\
\hline 4 & $\begin{array}{l}\text { Halaman } \\
\text { Kompetensi }\end{array}$ & Memilih Tombol "Navigasi" & Blackbox & $(\sqrt{ })$ Berhasil \\
\hline \multirow{4}{*}{5} & \multirow{4}{*}{$\begin{array}{l}\text { Halaman Video } \\
\text { Pembelajaran }\end{array}$} & Memilih Tombol "Navigasi" & Blackbox & $(\sqrt{ })$ Berhasil \\
\hline & & Memilih Tombol "Volume" & Blackbox & $(\sqrt{ })$ Berhasil \\
\hline & & Memilih Tombol "Pause" & Blackbox & $(\sqrt{ })$ Berhasil \\
\hline & & Memilih Tombol "Play" & Blackbox & $(\sqrt{ })$ Berhasil \\
\hline 6 & Halaman Quiz & Memilih Tombol "Navigasi" & Blackbox & $(\sqrt{ })$ Berhasil \\
\hline 7 & Halaman Petunjuk & Memilih Tombol "Navigasi" & Blackbox & $(\sqrt{ })$ Berhasil \\
\hline 8 & Halaman Tentang & Memilih Tombol "Navigasi" & Blackbox & $(\sqrt{ })$ Berhasil \\
\hline \multirow[t]{3}{*}{9} & \multirow{3}{*}{$\begin{array}{l}\text { Halaman } \\
\text { Simulasi Ujian }\end{array}$} & Memilih Tombol "Navigasi" & Blackbox & $(\sqrt{ })$ Berhasil \\
\hline & & Memilih Tombol "Simulasi UTS” & Blackbox & ( $\sqrt{ })$ Berhasil \\
\hline & & Memilih Tombol "Simulasi UAS” & Blackbox & $(\sqrt{ })$ Berhasil \\
\hline
\end{tabular}

6. Pendistribusian (Distribution)

Tahap distribusi merupakan tahap yang dilakukan setelah aplikasi dinyatakan layak pakai (Nurajizah, 2016). Dalam tahapan ini, aplikasi akan disimpan di dalam media penyimpanan seperti harddisk atau SD card. Ini merupakan tahap akhir dimana aplikasi yang sudah jadi telah diubah kedalam bentuk .apk dan siap untuk digunakan atau digandakan untuk tujuan publikasi. Aplikasi multimedia pembelajaran interaktif untuk mahasiswa berkebutuhan khusus ini dibuat menggunakan 
Articulate Storyline 3 yang kemudian diubah kedalam bentuk apk menggunakan aplikasi Website 2 APK Builder agar aplikasi tersebut dapat dijalankan di perangkat Android.

Dalam melakukan penelitian ini penulis mendapati beberapa keterbatasan temuan diantaranya aplikasi multimedia pembelajaran interaktif ini tidak multi-platform, hanya dapat digunakan pada Android saja. Selain itu, aplikasi multimedia pembelajaran interaktif ini dibuat hanya untuk mata kuliah Algoritma dan Pemrograman Dasar saja dan belum dikembangkan di mata kuliah pokok lainnya. Penulis harap penelitian ini bisa dijadikan sebagai referensi bagi pengembangan dan penelitian selanjutnya baik oleh kami maupun peneliti lain.

\section{Kesimpulan}

Berdasarkan hasil penelitian, maka dapat disimpulkan bahwa penelitian ini menghasilkan sebuah aplikasi multimedia pembelajaran interaktif berbasis Android untuk mahasiswa berkebutuhan khusus di lingkungan Prodi Sistem Informasi UNIKOM yang dinamakan Aplikasi Multimedia Pembelajaran Interaktif (AMPI) Algoritma Teori. Hasil penelitian ini diharapkan dapat menciptakan proses belajar yang lebih efektif terutama dalam lingkungan Prodi Sistem Informasi sehingga perhatian mahasiswa berkebutuhan khusus tidak mudah teralihkan dan mereka lebih mudah menyerap materi yang diajarkan oleh dosen.

\section{Daftar Rujukan}

Ambarwati, P., \& Darmawel, P. S. (2020). Implementasi Multimedia Development Life Cycle Pada Aplikasi Media Pembelajaran Untuk Anak Tunagrahita. Majalah Ilmiah UNIKOM, 18(2), 51-58. https://doi.org/10.34010/miu.v18i2.3936

Barakati, D. P. (2013). Dampak Penggunaan Smartphone dalam Pembelajaran Bahasa Inggris (Persepsi Mahasiswa). Jurnal Elektronik Fakultas Sastra Universitas Sam Ratulangi, 1(1), 1-13. Retrieved from https://ejournal.unsrat.ac.id/index.php/jefs/article/view/1820

Hakim, M. L. (2020). Multimedia Interaktif Bagi Siswa Berkebutuhan Khusus. Al-Aulad: Journal of Islamic Primary Education, 3(1), 48-55. https://doi.org/10.15575/al-aulad.v3i1.5903

Hardiyana, B., \& Yudistira, R. (2018). Application of IPS Learning about Humans and Geographical Environment Based on Multimedia. IOP Conference Series: Materials Science and Engineering, 407(1). https://doi.org/10.1088/1757-899X/407/1/012132

Isroqmi, A. (2017). Kemampuan Mahasiswa Memahami Logika Pemrograman Komputer Melalui Algoritma. Nabla Dewantara: Jurnal Pendidikan Matematika, 2(November), 59-74.

Jauhari, J. (2009). Studi Terhadap Penggunaan Multimedia Interaktif Dalam. Prosiding Seminar Nasional Penelitian, Pendidikan Dan Penerapan MIPA, 425-432.

Maulidiyah, F. N. (2020). Media Pembelajaran Multimedia Interaktif Untuk Anak Tunagrahita Ringan. Jurnal Pendidikan, 29(2), 93-100. https://doi.org/10.32585/jp.v29i2.647

Mustika, M., Sugara, E. P. A., \& Pratiwi, M. (2018). Pengembangan Media Pembelajaran Interaktif dengan Menggunakan Metode Multimedia Development Life Cycle. Jurnal Online Informatika, 2(2), 121. https://doi.org/10.15575/join.v2i2.139

Nurajizah, S. (2016). Implementasi Multimedia Development Life Cycle Pada Aplikasi Pengenalan Lagu Anak-Anak. Jurnal PROSISKO, 3(2), 15.

Rohman, U. (2019). Buana Pendidikan: Jurnal FKIP Unipa Surabaya Tahun XV, No. 27. Februari 2019. Jurnal Buana Pendidikan, (27), 120-126. 